\title{
Synthesis of biphenyl-based arsine ligands by microwave- assisted Suzuki-Miyaura coupling and their applications
}

\author{
Gisela J. Quinteros, Sandra E. Martín* \\ INFIQC, Departamento de Química Orgánica, Facultad de Ciencias Químicas, Universidad Nacional de \\ Córdoba, 5000-Córdoba, Argentina \\ *e-mailmartins@fcq.unc.edu.ar
}

Keywords: arsine ligands, Suzuki-Miyaura, microwave

\section{INTRODUCTION}

Over the past few years, there has been a growing interest in the synthesis and application of biphenylbased monophosphine ligands. ${ }^{1}$ Although tertiary phosphines constitute the group of ligands most widely used in metal-catalyzed reactions, arsines have been shown to be excellent ligands and there are several examples where arsine complexes give more active or selective catalysts than phosphines.

We have developed a versatile methodology that allow for C-As bond formation through a Pdcatalyzed arsination with stannane $n-\mathrm{Bu}_{3} \mathrm{SnAsPh}_{2}{ }^{2}$ By this methodology we carried out the synthesis of a novel biphenylarsine ligand biphenyl-2yldiphenylarsine, and also the preliminary investigation of its performance as a ligand. ${ }^{2 a}$

Herein, we report the synthesis of a family of biarylarsine ligands (Figure 1) by an approach, including first the $\mathrm{Pd}$-catalyzed arsination, and then the microwave-assisted Suzuki-Miyaura coupling as the key synthetic tool for biaryl construction. Additionally, the activity of new biarylarsine ligands in Pd-catalyzed reactions is also reported.

\section{RESULTS AND DISCUSSION}

By the Pd-catalyzed arsination with $n-\mathrm{Bu}_{3} \mathrm{SnAsPh}_{2}$ (1), the (2-bromophenyl)diphenylarsine $(2,83 \%)$ was obtained. ${ }^{2 a}$ The Suzuki-Miyaura coupling reaction between bromoarsine 2 and aryl boronic acids bearing different substituents provided biarylarsine ligands L1-L9 in very good (66-99\%) (Scheme 1).
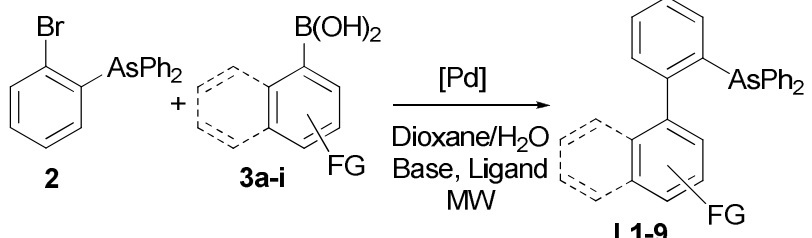

$\mathrm{FG}=\mathrm{H}(3 \mathbf{a}) ; 2-\mathrm{Me}(3 \mathbf{b}) ; 2,6$-diMe (3c); 2,4,6-triMe (3d); 2-OMe (3e); 2,6-diOMe (3f); 4-NMe 2 (3g); 2-CF 3 (3h); Naph (3i)

Scheme1. Insert the figure caption her

The coupling reaction conditions were thoroughly optimized, and we explored different methods and system for MW irradiation.

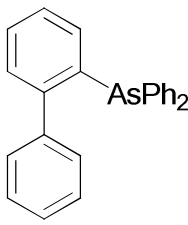

L1

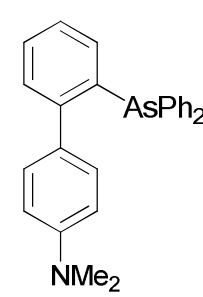

L7

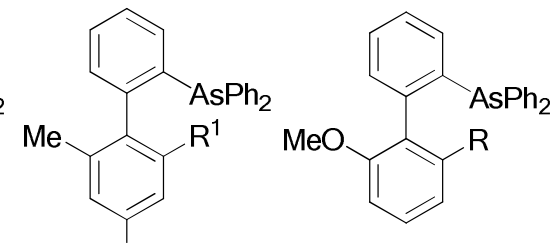

$\mathrm{R}^{2}$

L2, $R^{1}, R^{2}=H$

L3, $R^{1}=M e, R^{2}=H$ $L 4, R^{1}, R^{2}=M e$

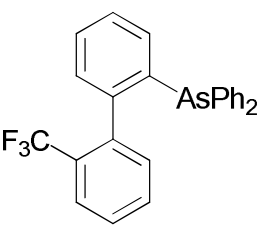

L8
L5, $\mathrm{R}=\mathrm{H}$ $\mathrm{L} 6, \mathrm{R}=\mathrm{OMe}$

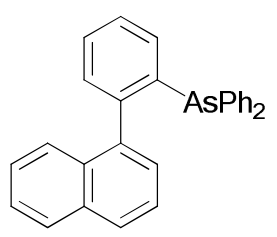

L9
Figure1. Insert the figure caption her

Despite of the considerably bulky - $\mathrm{AsPh}_{2}$ moiety in $\mathbf{2}$ and boronic acids with two groups in the ortho positions, the reaction was successfully carried out. The efficiency of catalysts derived from the new biarylarsine ligands was evaluated in $\mathrm{Pd}$-catalyzed Stille and Heck. The Pd/L4 and L6 based catalysts demonstrated significant activity for both coupling reactions with 4-bromoanisol.

\section{CONCLUSION}

We have synthesized a new family of biarylarsine ligands with different steric and electronic properties, varying the substituents in the biaryl backbone. Our newly prepared biphenylarsine ligands show promised activity for Pd-catalyzed reactions.

\section{ACKNOWLEDGEMENTS}

We are grateful to ACC, CONICET, FONCYT and SECYTUNC for financial support.

\section{REFERENCES}

${ }^{1}$ (a) Martin, R.; Buchwald, S. L. Acc. Chem. Res. 2008, 41, 1461. (b) Fu, G. C. Acc. Chem. Res. 2008, 41, 1555.

2 (a) Bonaterra, M.; Martín, S. E.; Rossi, R. A. Org. Lett. 2003, 5, 2731. (b) Uberman, P. M.; Lanteri, M. N; Martín, S. E. Organometallics 2009, 28, 6927.

$14^{\text {th }}$ Brazilian Meeting on Organic Synthesis $-14^{\text {th }}$ BMOS - September 01-05, 2011-Brasilia, Brazil 